\title{
A ENFERMAGEM E A CRISE ATUAL: ÉTICA, COMPROMISSO E SOLIDARIEDADE
}

\author{
Cristina Maria Loyola Miranda*
}

\begin{abstract}
RESUMO: Este trabalho aborda a atual crise pela qual passa a Enfermagem, porém, através de uma análise que focaliza esta crise, dentro de um processo social mais amplo e abrangente, no qual a saúde é apenas um dos possiveis aspectos. A formação profissional é a questão específica baseada em três pontos principais: dinâmica da formação; sistematização e consolidação do conhecimento de Enfermagem, e finalmente, a participação da enfermeira na prestação e qualidade dos serviços de saúde.
\end{abstract}

\begin{abstract}
This paper covers the present nursing crisis, by means of an analysis concerned with this crisis inside a wider and surrounding social process, where health is only one of many possible aspects. The professional formation is the specific question based upon three main points: graduation dynamics; systematization and consolidation of nursing knowledge and finally, nurses participation on health services assistance and quality.
\end{abstract}

Falar da crise do setor saúde no Brasil, e da crise que a Enfermagem sof re, porque é uma das parceiras deste processo, é refletir sobre uma situação do micro-social, porém, tendo a lucidez de se aperceberque esta crise é o desdobramento de uma outra crise mais ampla, que de certa forma abrange a maior parte das ciências e mesmo a totalidade da CULTURA, aqui entendida como toda inf ormação extra-genética.

A nossa caminhada enquanto profissão no Brasil ainda é incipiente, se estabelecermos uma comparação, por exemplo, com o caminho que resultou na drástica mudança de conceitos e idéias que ocorreu na Física, durante os primeiros trinta anos do século, e que ainda está sendo elaborada nas atuais teorias da matéria. (1) Esses novos conceitos em Física, onde se passou da concepção mecanicista de Descartes e Newton, para a visão holística e da natureza da física quântica, não foram, em absoluto, facilmente aceitos pelos cientistas do começo do século. A exploração do mundo atômico e subatômico colocou os físicos em contato com uma estranha e inesperada realidade, que parecia desafiar qualquer descrição coerente. Nesse esforço de apreender a nova realidade, tornouse irremediavelmente claro, que sua linguagem, seus conceitos básicos, e todo o seu modo de pensar, eram inadequados para descrever fenômenos atômicos.

Entre o exemplo da Física e as questões pertinentes à situação atual da Enfermagem brasileira, o que existe são apenas facetas dif erentes de uma só crise, que é essencialmente, uma crise de percepção. Tal como a crise da década de 20 da Física, a atual, a nossa, deriva de um grande esforço vão, de um enorme desgaste de energia, onde estamos tentando aplicar os conceitos de uma visão de mundo obsoleta - a visão de mundo mecanicista da ciência Newtoniana/Cartesiana - para apreender uma realidade que já não pode ser entendida em função destes conceitos. $\mathrm{O}$ mundo de hoje, da informática veloz na própria superação de suas novidades, é um mundo interliga$d o$, no qual os fenômenos biológicos, sociais e ambientais são todos interdependentes. (3)

Para viver neste mundo harmoniosamente, sem sofrer esta dolorosa sensação de "alienação", este desconforto de estar como que "fora do compasso" da história e da política, nós necessitamos de uma perspectiva ecológica, da ecologia humana que, definitivamente, a visão de mundo cartesiana não nos oferece. As limitações dessa visão de mundo e do sistema de valores em que se assenta, estão afetando seriamente nossa saúde individual e nossa proposta

* Prof essora Adjunta do Departamento de Enfermagem Médico-Cirúrgica da EEAN/UFRJ. Doutoranda do Instituto de Medicina Social da UERJ. 
social. Para retomar o exemplo da Física (e não é por acaso que a vanguarda epistemológica no mundo é composta em grande parte por cientistas desta área), a visão de mundo sugerida pela física moderna não é compativel com a nossa sociedade atual, socicdade esta que não reflete o harmonioso estado de inter-relacionamento que observamos na natureza. Mas este estado de equilíbrio não é mais estático, como supunha a visão mecanicista. mas sim complexo e absolutamente dinâmico, para o qual torna-se necessário uma estrutura social e econômica radicalmente diferente, uma revolução cultural na acepção mesma da palavra.

Antes de focarmos a Enfermagem propriamente dita, enquanto formação do profissional, vamos dar um rápido "olhar" nos conceitos mais amplos desta crise mundial, que pode af etar a cada um de nós indiscriminadamente:

- Estocamos dezenas de milhares de armas nucleares, suficientes para destruir o mundo inteiro várias vezes, e a corrida armamentista prossegue a uma velocidade incoercível ${ }^{(1)}$.

- Os custos dessa loucura nuclear coletiva são assustadores. Em 1978, ${ }^{(3)}$ os gastos militares mundiais eram de cerca de 425 bilhões de dólares - mais de 1 bilhão dólares/dia.

- Enquanto isso, mais de 15 milhões de pessoas - em sua maioria crianças - morrem anualmente de fome e outros 500 milhões de seres humanos estão gravemente subnutridos.

- Aproximadamente $40 \%$ da população mundial não tem acesso a serviços profissionais de saúde, e os países em desenvolvimento gastam três vezes mais em armamentos do que em assistência à saúde.

- Aproximadamente $35 \%$ da humanidade não tem acesso a água potável, enquanto metade dos cientistas e engenheiros dedica-se à tecnologia da fabricação de armas. ${ }^{(1)}$

Afastando-nos um pouco da crise micro-social, para não dizer da crise do nosso planeta, que é importante para manter a imagem de fundo desta nossa outra crise, mais específica, vamos levantar alguns questionamentos acerca da formação profissional da enfermeira.

Toda a sociedade, ou no mínimo, toda a comunidade da Enfermagem, deveria estaratenta à qualidade deste profissional formado. E esta formação deveria abranger alguns aspectos, a saber:
1. A dinâmica da formação

2. A inscrição do profissional no processo de produção.

3. As características e situações da forma de trabalho de Enfermagem no contexto da força de trabalho em saúde.

4. A criação e utilização de novas tecnologias e a questão das patentes, campos pouquíssimos explorados ainda, na nossa prática diária.

5. A produção, consolidação e sistematização do conhecimento da Enfermagem.

6. A relação entre organização do sistema de saúde e a formação em Enfermagem.

7. A participação da enfermeira na prestação e qualidade dos serviço de saúde, entre outros.

Dentre as várias questões possíveis neste assunto, gostaria de relevar neste artigo, três pontos, a título mesmo de provocar uma discussão:

$1^{\circ}$ ) A dinâmica da formação.

$2^{\circ}$ ) A produção, consolidação e sistematização do conhecimento da enfermagem.

$3^{\circ}$ ) A participação da enfermeira na prestação e qualidade dos serviços de saúde, para que possamos ensaiar uma relação entre três itens e a crise maior da qual já delineamos alguns pontos.

É conhecida a insatisfação de docentes e discentes com respeito ao modo pelo qual o Currículo de Graduação em Enfermagem vem sendo desenvolvido. E as razões também não são segredo: multiplicação desordenada de disciplinas, a falta de definição do tipo de profissional que se dese ja formar, a insistência de uma estrutura curricular inadequada ao planejamento e à execução dos programas de ensino. Tudo isto sem falar na repetição pura e simples de conteúdos teóricos e de atividades práticas ao longo do curso, que dificultam a integração, a sequenciação lógica e a unidade do pensamento, quanto ao enfoque do ensino, às estratégias metodológicas e às prioridades para o desenvolvimento de competências. (5)

Partindo da consideração que existe um Curriculo Oculto (planejamento, organização, olhar, tocar, sorrir, permitir/proibir, conceder, bibliografia, economia das paixões e dos sentidos) e um Currículo Oficial, que é o formal. Vamos definir este último como sendo tudo aquilo que diz respeito à atividade formal mesmo, planejada como parte do Currículo e também como Currículo informal, as atividades extra-curricu- 
lares que muitas veces sĩo tanto. ou atć mais significativas. Em cstudo por nós realizado cm 1987. (5) cis o que cncontramos quanto às Instituições de Ensino Supcrior na região Sudestc:

1. $44 \%$ destas instituiçõcs adotam o sistcma formal de cnsino. A prcocupação principal não ć a dc detcrminar " quic o cstudante deve tornar-sc capa\%. de fa/cr. c a partir daí. o que cle precisa saber para tomar-se capaz de desempenhar a contento suas atividades. Em nossas cscolas. ainda cstamos utilizando como criterio para seleção do contericto rérico de unna disciplina aquele de abranger as patologias mais importantes. Alćm de obedecer ao modclo bio-mćdico mecanicista/obsolcto. como já vimos. fica transparente que $\mathrm{cm}$ grande parte das cscolas de cnfermagem. a prática ć determinada pela tcoria. que já foi sclecionada $a$ priori. É neccssário então procurar aridamente na realidade do social. um "recorte". que possa conter aquilo que já foi cnsinado tcoricamente na sala de aula. Inverte-se completamente a direção do movimento. () real. dentro das limitações da sua aprecnsão, no lugar de despertar questionamento. dúvidas. reflexiõcs. diálogo crítico. que ć o que compõc a sua rique $\%$ a. passa a ocupar a situação de complementar à camisa de força da tcoria. ${ }^{(5)}$

Qucremos destacar aqui. que a cstrutura interna do Currículo tradicional c do tipo tcórico-dedutiva. o que implica que se parta das premissas gerais da ciência. formalizadas cm disciplinas (nível abstrato). para depois abordar as situaçõcs práticas (nível concreto). Supõc-sc que os alunos. informados da tcoria. rcalìarão uma aplicação automática c adcquada diante de casos concretos. o que é no mínimo questionável. Sabcmos que os csquemas de assimilaçào do nosso alunado são predominantemente do tipo lógico-concreto c não lógico-abstrato. Esta pedagogia produz avanços limitados no conhecimento da realidade específica, na claboração de soluções adaptadas às mesmas. favorecendo a difusĩo de conhecimentos processados $\mathrm{cm}$ outros contcitos. Produ\% cscasso aranço intelectual. freqüentementc formando cabcças informadas. ao invés de pessoas críticas c pensantcs. porque não supera a contradiçâo entre conlıccimento parcelado c realidade totalizadora. (5) Na realidade, o desenvolvimento da consciência crítica der c scr o fim último da cducação. É necessário falar aqui sobre a importancia da pesquisa na grachuação. porque gostaria de corrclacioná-la com o que scria o $2^{\prime \prime}$ ponto. a produção. consolidação c sistcmatiıação do conhecimento da Enfermagem
A partir de uma abordagem bastante dircta $c$ objetiva. a proposta ć a de colocar a pesquisa, não apcnas como base das lides científicas. mas também como base do processo de formação cducativa. $\mathrm{cm}$ todos os nír cis de cnsino. c no nosso caso. o nível de graduação. Pesquisa não se cnsina. pesquisa se faz c se aprende faycndo. ${ }^{(4)}$ E nesta caminhada. o mćtodo ć apcnas a forma mais adequada para tratar o objeto de investigação. É um mcio. não ć um fim.

Nós tcmos. na Enfermagem brasilcira. a moda ainda atual para nós. (completamente demodée para a sociologia francesa. por c.remplo). de termos professoras "cspecialistas" do mćtodo. numa verdadcira guerra de adıcrsárias insanas. no equívoco de uma luta por um método dito "certo" (atualmentc. o matcrialismo histórico) contra um. "crrado" (no caso. o positivismo). quando o quê cxistc ć o mćtodo adequado. ou inadcquado. para tratar tal objeto.

Nós. na Enfermagem. nas cscolas c mais ainda. nos serviço de assistência. precisamos correr para desmistificar a pesquisa, para não cncerrá-la cm sofisticaçõcs operáveis apenas por castas supcriores c raras, reservada a clicntes especiais. ${ }^{(4)}$ Temos que tcntar, na graduação, cotidianizar a pesquisa, como processo normal de formação histórica das pessoas c grupos. significando condição de domínio da realidade que nos circunda.

\section{Ou a pesquisa poderia ter o conceito de reintroduzir a adequaçãon entre teoria e prática, ou que evite, no minmmo a fuga da Lniversidade para o mundo da lua. (4)}

A pesquisa tambćm se torna formação cducativa. quanto se funda no csforço sistcmático c inv cntivo de claboração própria. atravćs da qual sc constrói um projeto de emancipação social c se dialoga criticamentc com a realidade. É uma currosidacle criativa. a condição de connciència critica para dialogar com a realidade

Tcmos pago um preço alto na academia. por convivermos com a separação artificial entre cnsino c pesquisa. A grande maioria dos professores só cnsina. scja porque não domina sofisticadas tćcnicas de pesquisa. mas sobrctudo porque admitc a cisão. como algo dado. Fc\% "opção" pelo cnsino. c passa a vida contando aos alunos o que aprendeu de outros. imilando c reproduzindo. No outro c.tremo, temos a soberba do professor pesquisador cxclusivo. que já considera o cnsino como atividade menor. c a concessão máxima que ‘ay ć ministrar aulas. c ainda nos Cursos de Pós-Graduação. 
Esta "mitologia da pesquisa" é toda passada ao aluno, para quem pesquisa, é coisa para pessoas muito sabidas. O pesquisador, como ator social, é fenômeno político, que na pesquisa se traduz sobretudo pelo interesses que mobilizam os confrontos e pelos interesses aos quais serve. Pesquisa é sempre fenômeno político, por mais que seja dotada de sofisticação técnica e se mascare de neutra. Não se reduz a fenômeno político, mas nunca o desfaz de todo, daí porque vale dizer: sabemos mais o que nos interessa. ${ }^{(4)}$

Em termos epistemológicos, ainda estamos na fase de classificar as coisas, ou melhor dizendo, não temos ainda um saber de Enfermagem consolidado, o que é tarefa para muitas décadas.

Faço então uma ponte com o $3^{\circ}$ ponto, " a participação da enfermeira na prestação e qualidade dos serviços de saúde" que eu listei inicialmente, como um dos pontos constantes da formação profissional.

Segundo CRISTOVAM BUARQUE, no seu livro "A desordem do progresso"'(1), as ciências, entre seu momentos extremos, passam por três fases: em primeiro momento, de simples explicadora, de fenômenos, abolindo a explicação ético-deísta; o segundo, em que adquirem um poder transformador, mantendo-se sem a necessidade de uma ética; e terceiro, quando o poder transformador atinge proporções catastróficas e leva o cientista a descobrir a necessidade de um novo comportamento ético, desta vez uma ética reguladora.

Não faltam exemplos desta proposta, como por exemplo, a evolução da Física de Galileu e Newton à Física Quântica, às primeiras experiências com a bomba atômica, até Nagasaki. A Física concluía seu ciclo de abolição da ética explicativa e passava a exigir uma ética reguladora.

Embora estejamos ainda no primeiro ponto do ciclo já cumprido pela Física, as mudanças para o $3^{\circ}$ milênio, tenderão a se acelerar muito. E a enfermeira precisa repensar e discutir a forma com que nossos recém-formados vêm se inserindo nos serviço de saúde e assegurando uma prestação de assistência.

O que nós temos presenciado, é uma rápida assimilação das distorções dos serviços de saúde pelas enfermeiras, e um acumpliciamento homogêneo com a má qualidade da assistência e com a sordidez da maior parte desses serviço. Esta questão, em última análise, passa por um questão ética, que também deveria estar presente na formação.

A forma concreta predominante nas práticas de assistência, evidencia uma abordagem funcional e a incorporação de uma concepção do social completamente esfacelada. Não se percebe o social organizado com as relações de produção e com a estrutura econômica, na qual o cliente está inserido. (2)

A partir do momento em que a idéia de progresso perneou toda a humanidade, e a economia apropriouse do conceito de modemidade, criou-se um fetiche aceito generalizadamente, pelo qual os povos passavam a ter um único destino, medido por padrões únicos e rígidos, e definidos pelo avanço técnico utilizado no seu processo de produção. Nesta concepção econômica liberal, o social é submetido ao econômico, dentro da idéia de que, a economia sendo dinâmica, a sociedade tem o atendimento social de que necessita. O Brasil é o caso extremo da aplicação desta política, visto que nos submetemos a uma sistemática política de crescimento econômico, com o mais radical abandono dos objetivos sociais. (1) $\mathrm{O}$ Brasil conta com indicadores econômicos de exportação, estrutura industrial, auto-suficiência em vários setores, agricultura mecanizada e outros, que neste final de século, definem modemidade. Neste caminhar de "modernidade", todos os indicadores de bem estar social, especialmente saúde e educação, se degradaram, com uma total submissão do social ao econômico.

Somos 120 milhões de pobres; destes, 53 milhões em nivel de miséria, dos quais 20 milhões vegetam em absoluta miséria; somos o $2^{\circ}$ maior bolsão de miséria do mundo; temos 25 milhões de crianças em estado de abandono total, ou de semi-abandono, forçado pela miséria das famílias. ${ }^{(1)}$

A mortalidade infantil média por ano, é de $87 / \mathrm{mil}$ crianças que nascem vivas. Das que sobrevivem, $30 \%$ atravessarão a vida e entrarão no próximo milênio sem aprender a ler; 100 milhões não completarão a quarta série de escolaridade. Apenas 9 em cada 100 terminarão o $2^{\circ}$ grau e apenas 2 ingressarão na Universidade, das quais não chegará a uma, a que terá nível universitário satisfatório.

Quando situo neste contexto a participação da enfermeira na prestação de serviços de saúde, quero dizer que, eticamente, é preciso definir de qual lado se está jogando, ou de quem nos tornaremos cúmplices.

O único caminho, é uma subversão no modo de ver o processo social no Brasil, submetendo o econômico ao social, e não o contrário.

Nós enfermeiras, precisamos definir o significado claro de criar ou destruir. Precisamcss avançar na 
posição de nos vermos como elementos sem responsabilidade para intervir e administrar o processo social. Esta é a doce posição dos filósofos sociais dos séc. XVII e XVIII, cuja motivação era somente explicar o funcionamento da sociedade, assim como a nossa, a das enfermeiras, seria apenas "cuidar" do continuum saúde-doença dos indivíduos. Esboçavase, à época, um dese jo de levar ao fenômeno social a neutralidade das ciências físicas, na simplificação máxima de reduzir o social, à noção de causa e efeito. Mas, por outro lado, mantendo um compromisso subordinado às premissas éticas do capitalismo e do discurso liberal.

É preciso um abrir de olhos urgente. Orgulhoso, em parte, pelos avanços da própria profissão, mas que, como um dos elementos do todo social, não criou apenas a transformação maravilhosa de um mundo eficiente; mas que seja também, capaz de perceber a miséria a ponto de reduzir o homem a ser parte do lixo; aculturação, a ponto de formarem-se sociedades enlouquecidas; depredação da natureza, a ponto de ameaçar-se o próprio futuro da espécie.

O desafio maior que se impõe às nossas inteligências, é o de nos conscientizarmos de que este país, este povo, não pode passar sem uma assistência de enfermagem séria, comprometida e solidária com os mais fracos.

O nosso saber, ou a nossa técnica, por competentes que sejam, ou possam vir a ser, nada significam, se não se perguntar para quê e para quem existem e operam, senão se perguntam $a$ quem servem, se não se perguntar se há conivência do sábio com o domi- nador. ${ }^{(6)}$

É preciso frisar que o conhecimento é um caminho sem volta.

Nós todos somos cúmplices desta realidade, porque a conhecemos de perto. E temos todos que despertar para a realidade de que, um país moderno, "um país que deu certo", é aquele em que cada pessoa tem um emprego, em que todos comem todo dia, em que toda criança vai à escola, em que todos têm moradia, em que todo velho e doente é amparado, em que todos têm acesso à assistência de saúde, e mais objetivamente, direito a uma assistência de enfermagem com nível de excelência.

Se não temos a certeza de estar of erecendo isto à população, estamos então desafiados a perguntar às nossas enfermeiras: enfermeira, qual é a sua utilidade?

A sua utilidade enfermeira, é a de lutar sempre pela vida com qualidade, pela transparência de todas as questões ético-políticas, pelos direitos de cidadania plena, e se for o caso, por uma morte com dignidade.

A sua utilidade enfermeira, é sempre, de forma inarredável, a difícil posição de lutar pelo grupo daqueles que são mais fracos. A possibilidade de multiplicar o exercício de uma enfermagem digna, ética, bela, que tenha a lucidez de ousar e a possibilidade sempre, de tentar saber como, e até que ponto, seria possível diferentemente.

Tenho certeza de que nó sabemos muito bem estas respostas, mas é preciso que ninguém mais permaneça com esta dúvida.

\section{REFERÊNCIAS BIBLIOGRÁFICAS}

1. BUARQUE, Cristovam. A desordem do progresso. Rio de Janeiro: Paz e Terra, 1990.

2. CASTELlANOS, Brigitta E.P. e SALUM, Maria J. A Mercantilização da saude e as propostas de sistematização da assistència de enfermagem: o que buscamos e a quem servimos. Mimeo, 18p. (s.d.)

3. CAPRA, Fritjof. O ponto de mutação. São Paulo: Cultrix, 1982.
4. DEMO, Pedro. Pesquisa, principio cientifico educativo. 2 ed São Paulo: Cortez, 1991.

5. MIRANDA, Cristina M.L. e SAUTHIER, Jussara $O$ ensino de enfermagem e os campos de prática. In: Seminário Nacional de Ensino Superior de Enfermagem. Anais... São Paulo: MEC/SESU/USP, 1987, p.65-115.

6. RIBEIRO, Darcy. Universidade para quê? Brasilia: UNB, 1986

Recebido para publicação em 2.12.92 